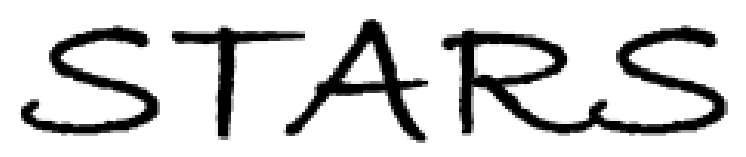

University of Central Florida

STARS

$1-1-1997$

\title{
Melting and vaporization for large-area film removal with a chemical oxygen-iodine laser
}

J. Xie

University of Central Florida

A. Kar

University of Central Florida

Find similar works at: https://stars.library.ucf.edu/facultybib1990

University of Central Florida Libraries http://library.ucf.edu

This Article is brought to you for free and open access by the Faculty Bibliography at STARS. It has been accepted for inclusion in Faculty Bibliography 1990s by an authorized administrator of STARS. For more information, please contact STARS@ucf.edu.

\section{Recommended Citation}

Xie, J. and Kar, A., "Melting and vaporization for large-area film removal with a chemical oxygen-iodine laser" (1997). Faculty Bibliography 1990s. 2140.

https://stars.library.ucf.edu/facultybib1990/2140

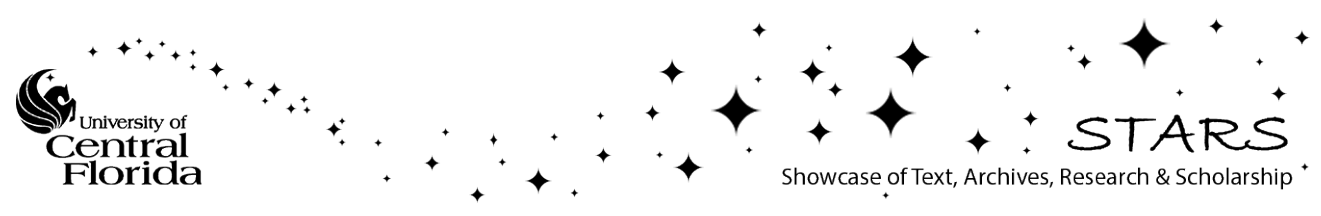




\section{Melting and vaporization for large-area film removal with a chemical oxygen-iodine laser}

Cite as: Journal of Applied Physics 82, 4744 (1997); https://doi.org/10.1063/1.366330

Submitted: 14 April 1997 . Accepted: 14 August 1997. Published Online: 04 June 1998

J. Xie, and A. Kar

\section{ARTICLES YOU MAY BE INTERESTED IN}

Theory of second harmonic generation in composites of nonlinear dielectrics

Journal of Applied Physics 82, 4740 (1997); https://doi.org/10.1063/1.366398

Lock-in Amplifiers

... and more, from DC to $600 \mathrm{MHz}$

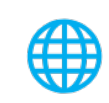

View Online 


\title{
Melting and vaporization for large-area film removal with a chemical oxygen-iodine laser
}

\author{
J. Xie and A. Kara) \\ Center for Research and Education in Optics and Lasers (CREOL), and Mechanical, Materials and \\ Aerospace Engineering Department, University of Central Florida, 4000 Central Florida Boulevard, \\ Orlando, Florida 32816-2700
}

(Received 14 April 1997; accepted for publication 14 August 1997)

\begin{abstract}
Large-area film removal with lasers is a physical process of melting and vaporization of films. A mathematical model is developed to simulate the melting and vaporization of films under the irradiation of a chemical oxygen-iodine laser. The cross section of the film after laser scanning and the substrate surface temperature during laser irradiation are presented. There is an optimum laser power at which relatively wide films can be removed by maintaining low temperature at the substrate surface. The optimum laser power is associated with other process parameters. The results of film removal with $\mathrm{TEM}_{31}$ and $\mathrm{TEM}_{00}$ beams are compared, and the laser mode with more uniform intensity distribution is found to be more effective for large-area film removal. (C) 1997 American Institute of Physics. [S0021-8979(97)08022-5]
\end{abstract}

\section{INTRODUCTION}

High-power industrial lasers are usually used for cutting, welding, and cladding. One of the latest applications of highpower lasers is the removal of large-area films from substrates. For example, all aircrafts with painted surfaces must be stripped and repainted on an average four-year cycle, ${ }^{1}$ and laser paint removal is considered as a potential technique to replace the expensive and hazardous conventional chemical and mechanical methods. ${ }^{1-8}$ The high-power lasers have been demonstrated for possible applications to remove hard coating (TiN or WC) from tools ${ }^{9}$ and embedded contamination from construction materials. ${ }^{10}$

Both pulsed ${ }^{1-3,5,6}$ and continuous wave ${ }^{2,3}$ lasers have been applied for large-area film removal. $\mathrm{CO}_{2}$, Nd:YAG, and excimer lasers are widely known lasers that can be suitable for such applications. ${ }^{1-6}$ Chemical oxygen-iodine laser (COIL) is another choice because it has short wavelengths $(\lambda=1.315 \mu \mathrm{m})$ close to the Nd:YAG laser $(\lambda=1.06 \mu \mathrm{m})$ and higher power than the Nd:YAG laser. The COIL beams can be transmitted by optical fibers instead of the mirror and tube system usually used for $\mathrm{CO}_{2}$ laser, because of the low transmission loss of COIL due to its short wavelength. However, COIL is still under development. McDermott et al. ${ }^{11}$ invented COIL in 1977, and Truesdell et al. ${ }^{12}$ demonstrated the engineering scalability of a supersonic gas flow COIL with $39 \mathrm{~kW}$ RotoCOIL device in 1989. This device used compact, rotating-disk, wetted-wall chemical reactors to generate large quantities of singlet delta oxygen, and then mixed the oxygen with iodine using a stacked supersonic nozzle array. ${ }^{13}$ Researchers have demonstrated the continuous operation of COIL for long durations. ${ }^{14-18}$ The principle of COIL has been discussed by Truesdell et al. ${ }^{12}$ and Avizonis and Truesdell $1{ }^{19}$ in details.

Fujioka reviewed the transmission of COIL through optical fibers to examine the industrial applications of such beam delivery systems. ${ }^{20}$ Atsuta et al. ${ }^{21}$ and Fujiii ${ }^{22}$ demon-

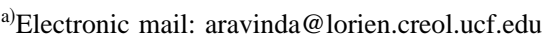

strated the transmission of a $1 \mathrm{~kW}$ COIL beam through a $300-\mu \mathrm{m}$ diameter silica fiber at an intensity of $1.4 \mathrm{MW} / \mathrm{cm}^{2}$. Atsuta et $\mathrm{al}^{21}$ investigated the cutting capability of COIL, and Kar et al. ${ }^{23,24}$ studied thick-section cutting with COIL. Xie and $\operatorname{Kar}^{25}$ obtained temperature-dependent absorptivity and compared the cutting capability for COIL, $\mathrm{CO}_{2}$, and $\mathrm{Nd}$ :YAG lasers. Although COIL has been used for cutting purposes, its application for film removal has not been reported in the available literature.

The purpose of this study is to consider the melting and vaporization processes to develop a mathematical model for large-area film removal with COIL. This model is used to examine paint removal from an aluminum substrate and the effects of laser modes and process parameters on film removal. The temperature rise at the substrate surface is also calculated, which is particularly important to avoid any damage to the substrate during the film removal process.

\section{MATHEMATICAL MODEL}

The laser beam of a typical COIL cavity is rectangular in shape, and consists of several modes. The heating characteristics of a multimode beam are different from a Gaussian $\left(\mathrm{TEM}_{00}\right)$ beam. ${ }^{24}$ Both multimode and Gaussian beams can be used for film removal from substrate surface. The geometric configuration for film removal is shown in Fig. 1, where a rectangular COIL beam of half-width $w_{1}$ and half-length $l_{1}$ moves in the $x$ direction with a constant velocity $\nu$.

Laser film removal involves melting and vaporization of the film. ${ }^{2,3,5,6,9}$ The film under the laser spot is heated up and finally vaporized away. The heat fluxes of interest at various sites are shown in Fig. 2, where $D$ is the film thickness, and $D_{V}$ and $D_{m}$ are the vaporization and melt depths, respectively. $q_{\mathrm{LV}}$ is the heat flux leaving the vaporization front, and $q_{\mathrm{Lm}}^{\prime}$ and $q_{\mathrm{Lm}}$ are the heat fluxes flowing into and out of the melting front, respectively. $I$ and $I_{\text {sub }}$ are the laser intensities at the vaporization front and film-substrate interface, respectively. 


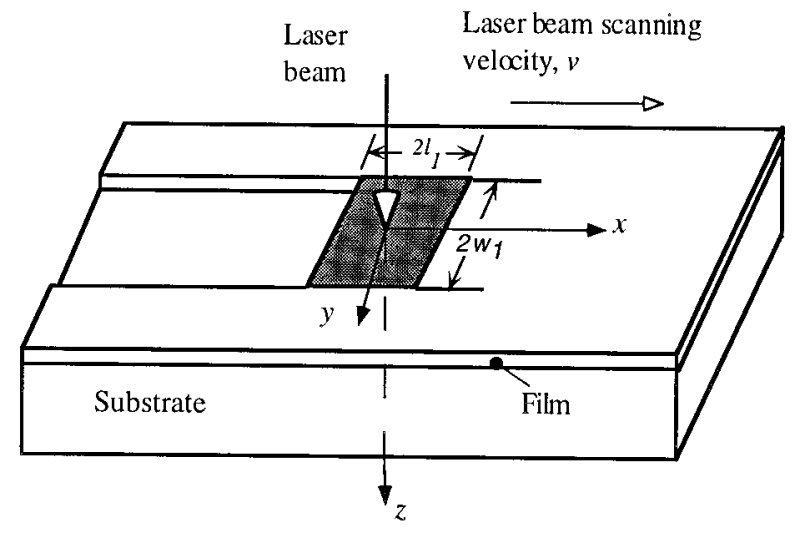

FIG. 1. Large-area film removal with a rectangular COIL beam.

The phase changes at the liquid-vapor and solid-liquid interfaces in the $z$ direction can be described by the Stefan condition as follows.

$$
\begin{aligned}
& \rho L_{V} \frac{d D_{V}}{d t}=I-q_{\mathrm{LV}} \quad \text { at the vaporization front } \\
& \rho L_{m} \frac{d D_{m}}{d t}=q_{\mathrm{Lm}}^{\prime}-q_{\mathrm{Lm}} \text { at the melting front, }
\end{aligned}
$$

where $\rho$ is the density of the film, and $L_{m}$ and $L_{V}$ are the latent heats of melting and vaporization, respectively. Equation (1) and (2) are subject to the initial conditions, $D_{V}(0)$ $=D_{m}(0)=0$. Under quasi-steady state condition, the liquidvapor interface travels at the same velocity as the solid-liquid interface, ${ }^{26}$ that is,

$$
\frac{d D_{V}}{d t}=\frac{d D_{m}}{d t}
$$

Usually, the melt layer is very thin for which the temperature distribution in the liquid layer may be assumed to be linear in the $z$ direction. Under this condition, the incoming heat flux $q_{\mathrm{Lm}}^{\prime}$ at the melting front is equal to the outgoing heat flux $q_{\mathrm{LV}}$ at the vaporization front, that is,

$$
q_{\mathrm{Lm}}^{\prime}=q_{\mathrm{LV}} .
$$

Substituting Eqs. (3) and (4) into Eqs. (1) and (2), $q_{\mathrm{LV}}$ is found to be

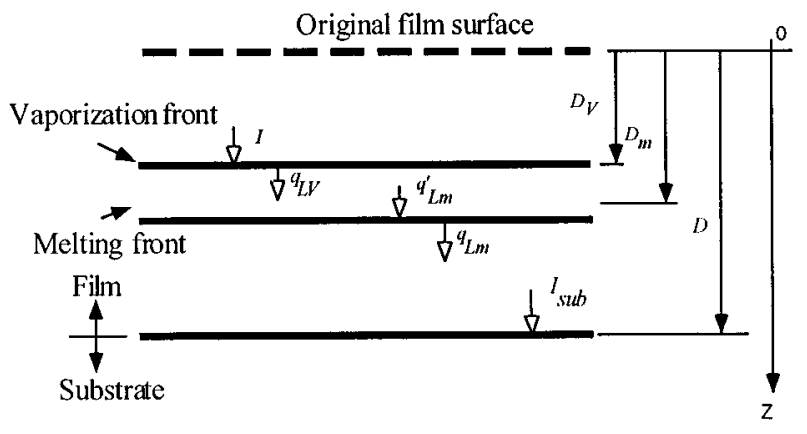

FIG. 2. Heat fluxes at various interfaces.

$$
q_{\mathrm{LV}}=\frac{L_{m} I+L_{V} q_{\mathrm{Lm}}}{L_{m}+L_{V}} .
$$

It should be noted that Eqs. (1) and (2) are obtained based on heat flow in the $z$ direction for a stationary laser beam with uniform intensity $I$. These equations are applicable within the entire laser spot when the spot is very large compared to the film thickness. In this study, the intensity $I$ is considered to vary in the $x$ and $y$ directions, that is, $I=I(x, y)$, which will cause heat conduction in these directions. The temperature in the $z$ direction drops from $T_{V}$ to the film-substrate interface temperature across the film. In the $x$ and $y$ directions, the temperature drops from $T_{V}$ to a temperature at the edge of the beam over larger distances giving rise to smaller temperature gradients than in the $z$ direction for laser beams of large spot size. So, the heat losses in the $x$ and $y$ directions can be neglected, and Eqs. (1) and (2) can be applied to large laser spot size and nonuniform intensity distribution. However, three-dimensional heat transfer needs to be considered for the substrate because of its large volume and high thermal conductivity compared to the film.

The transient solutions of Eqs. (1) and (2) are applied to the quasisteady state moving beam problem by evaluating $D_{V}(t)$ and $D_{m}(t)$ at the laser-material interaction times $t$ of various points in the workpiece. $t$ is given by

$$
t=\frac{l_{1}-x}{\nu} .
$$

The vaporization and melt depths due to the intensity at any point $(x, y), I(x, y)$, are calculated from Eqs. (1) and (2), respectively, corresponding to the interaction time for that point as given by Eq. (6), and then the results are integrated with respect to $x$ for fixed $y$ to account for the motion of the laser beam in the $x$ direction. This yields the cumulative depths and provides a simple method to investigate the topology of the laser-irradiated region through the proposed hybrid model as discussed below.

The intensity of a COIL beam, $I$, is given by

$$
I=\sum_{m=0}^{M} \sum_{n=0}^{N} I_{m n}
$$

where $M$ and $N$ are the largest mode numbers of the beam in the $x$ and $y$ directions, respectively. $I_{m n}$ is the intensity of the rectangular beam of $m$ th and $n$th order modes, which is given by

$$
I_{m n}=I_{0} H_{m}^{2}\left(\frac{\sqrt{2} x}{l_{10}}\right) H_{n}^{2}\left(\frac{\sqrt{2} y}{w_{10}}\right) \exp \left(-\frac{2 x^{2}}{l_{10}^{2}}\right) \exp \left(-\frac{2 y^{2}}{w_{10}^{2}}\right),
$$

where

$$
I_{0}=\frac{2 A P_{m n}}{2^{m+n} \pi m ! n ! l_{10} w_{10}}
$$

and $P_{m n}$ is the total power of the laser beam of $m$ th and $n$th order modes. $l_{10}$ and $w_{10}$ are, respectively, the half-length and half-width of the Gaussian mode. If $l_{1}$ and $w_{1}$ are, respectively, the half-length and half-width of the spot for the beam with $\mathrm{TEM}_{m n}$ mode, $l_{1}$ and $w_{1}$ are related to Gaussian spot size by the expressions, $l_{1}=l_{10} \sqrt{2 m+1}$ and $w_{1}$ $=w_{10} \sqrt{2 n+1} . A$ is the absorptivity of the film. $H_{m}$ and $H_{n}$ 
are, respectively, $m$ th and $n$th degree Hermite polynomials for the $m$ th and $n$th order modes of the laser beam.

The heat flux that reaches the substrate surface, $I_{\text {sub }}$, has similar intensity distribution as the incident laser intensity $I$, and its value is the difference between the incident laser intensity and the energy utilized to heat, melt, and vaporize the film per unit area per unit time, that is,

$$
I_{\text {sub }}=\left(I_{\text {sub }}\right)_{0} H_{m}^{2}\left(\frac{\sqrt{2} x}{l_{10}}\right) H_{n}^{2}\left(\frac{\sqrt{2} y}{w_{10}}\right) \exp \left(-\frac{2 x^{2}}{l_{10}^{2}}\right) \exp \left(-\frac{2 y^{2}}{w_{10}^{2}}\right),
$$

where

$$
\begin{aligned}
& \left(I_{\text {sub }}\right)_{0}=I_{0}\left[1-\frac{\rho\left[L_{V}+L_{m}+c_{P}\left(T_{V}-T_{0}\right)\right] \frac{d D_{V}}{d t}}{I_{\text {ave }}}\right] \\
& I_{\text {ave }}=\frac{A \sum_{m} \sum_{n} P_{m n}}{\left(2 l_{1}\right)\left(2 w_{1}\right) / \sqrt{(2 m+1)(2 n+1)}} .
\end{aligned}
$$

$I_{\text {ave }}$ is the average power density based on the area of the rectangular spot of the beam. $\left(d D_{V} / d t\right)$ in Eq. (11) can be represented approximately by the average vaporization velocity, $(H / \tau)$, where the interaction time $\tau$ is given by

$$
\tau=\frac{2 l_{1}}{\nu} .
$$

Therefore, $\left(I_{\text {sub }}\right)_{0}$ can be written as

$$
\left(I_{\text {sub }}\right)_{0}=I_{0}\left[1-\frac{\rho\left[L_{V}+L_{m}+c_{P}\left(T_{V}-T_{0}\right)\right]}{A \sqrt{(2 m+1)(2 n+1)} \sum_{m} \sum_{n} P_{m n}}\left(2 w_{1}\right) \nu H\right] .
$$

The heat flux $q_{\mathrm{Lm}}$ is approximately equal to $I_{\text {sub }}$ because the thermal energy absorbed by the solid film below the melting front is usually very small for thin films. However, due to the effect of the interaction time at different locations in the $x$ direction, the heat flux $q_{\mathrm{Lm}}$ is taken equal to $I_{\text {sub }}$ varying with $x$. Assuming linear variation of $I_{\text {sub }}$ with $x, q_{\mathrm{Lm}}$ can be represented by

$$
q_{\mathrm{Lm}}=I_{\text {sub }} \frac{l_{1}-x}{2 l_{1}} .
$$

Also, due to the linear temperature variation along the $z$ direction in the melt, the heat flux $q_{\mathrm{LV}}$ can be expressed as

$$
q_{\mathrm{LV}}=k_{l} \frac{T_{V}-T_{m}}{D_{m}-D_{V}} .
$$

The thickness of the melt, $\left(D_{m}-D_{V}\right)$ can be obtained from Eqs. (5), (15), and (16) as follows

$$
D_{m}-D_{V}=\frac{k_{1}\left(L_{V}+L_{m}\right)\left(T_{V}-T_{m}\right)}{L_{m} I+L_{V} I_{\text {sub }}\left(l_{1}-x\right) /\left(2 l_{1}\right)} .
$$

TABLE I. Thermophysical properties of polymers and aluminum. ${ }^{a, b}$

\begin{tabular}{lcc}
\hline \hline & Polymers & Aluminum \\
\hline Density $\rho\left(\mathrm{kg} / \mathrm{m}^{3}\right)$ & 1200 & 2700 \\
Specific heat $c_{P}\left(\times 10^{3} \mathrm{~J} / \mathrm{kg} \mathrm{K}\right)$ & 2.0 & 0.899 \\
Latent heat of melting $\left(\times 10^{5} \mathrm{~J} / \mathrm{kg}\right)$ & 0.65 & 0.97 \\
Latent heat of vaporization $\left(\times 10^{5} \mathrm{~J} / \mathrm{kg}\right)$ & 2.72 & 112.97 \\
Melting temperature $(\mathrm{K})$ & 473 & 933 \\
Thermal decomposition temperature $(\mathrm{K})$ & 593 & \\
Thermal conductivity $(\mathrm{W} / \mathrm{mK})$ & 0.2 & 92 \\
Thermal diffusivity $\left(\times 10^{-6} \mathrm{~m}^{2} / \mathrm{s}\right)$ & 0.1 & 38 \\
\hline \hline
\end{tabular}

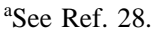

${ }^{\mathrm{b}} \mathrm{See}$ Ref. 29.

Substituting Eqs. (5), (6), and (15) into Eq. (1) and integrating the resulting expression, the vaporization depth is given by

$$
D_{V}=\frac{1}{\rho \nu\left(L_{V}+L_{m}\right)} \int_{x}^{l_{1}}\left(I-I_{\text {sub }} \frac{l_{1}-x}{2 l_{1}}\right) d x .
$$

During the film removal process, a fraction of the laser energy is absorbed by the film, and the rest is conducted to the substrate increasing its temperature. It is very important to control the substrate surface temperature to avoid any damage, at least no melting, of the substrate. By using the heat flux $I_{\text {sub }}$ from Eq. (10) in the three-dimensional heat conduction model of Kar et al., ${ }^{24}$ the temperature distribution in the substrate can be shown to be

$$
\begin{aligned}
T(x, y, z)= & \frac{\exp (-b x)}{\pi} \sum_{m=0}^{M} \sum_{n=0}^{N} a_{m n} \int_{0}^{\infty} r^{\prime} d r^{\prime} \\
& \times f_{m}\left(x-r^{\prime} \cos \theta\right) \int_{0}^{\pi} d \theta g_{n}\left(y-r^{\prime} \sin \theta\right) \\
& \times \frac{\exp \left(-b \sqrt{r^{\prime 2}+z^{2}}\right)}{\sqrt{r^{\prime 2}+z^{2}}}
\end{aligned}
$$

where

$$
\begin{aligned}
& T(x, y, z)=\frac{T_{1}(x, y, z)-T_{0}}{T_{m}-T_{0}} \\
& b=\frac{\nu}{2 \alpha} \\
& a_{m n}=\frac{\left(I_{\text {sub }}\right)_{0}}{k\left(T_{m}-T_{0}\right)} \\
& f_{m}(x)=H_{m}^{2}\left(\frac{\sqrt{2} x}{l_{10}}\right) \exp \left(b x-\frac{2 x^{2}}{l_{10}^{2}}\right) \\
& g_{n}(y)=H_{n}^{2}\left(\frac{\sqrt{2} y}{w_{10}}\right) \exp \left(-\frac{2 y^{2}}{w_{10}^{2}}\right) .
\end{aligned}
$$

The temperature, $T(x, y, z)$ in Eq. (19) is the dimensionless normalized temperature of the substrate as defined by Eq. (20), $T_{1}(x, y, z)$ and $T_{0}$ are the actual and initial temperatures of the substrate, respectively, and $T_{m}$ is the melting point of the film. $\alpha$ is the thermal diffusivity of the substrate. The integrals in Eq. (19) are numerically evaluated using the trapezoidal rule for numerical integration to calculate the temperature distribution at the substrate surface for various process parameters. 


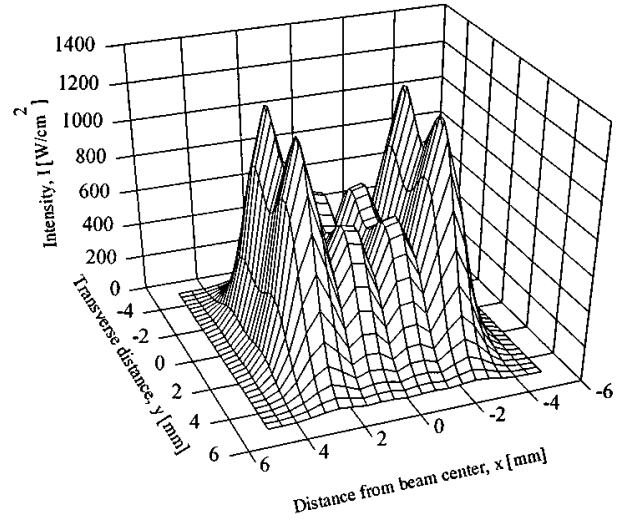

FIG. 3. Three-dimensional intensity distribution of a $\mathrm{TEM}_{31}$ COIL beam $\left(P=450 \mathrm{~W}, 2 l_{1}=2 w_{1}=10 \mathrm{~mm}\right)$.

The mathematical model represented by Eqs. (17)-(19) can be used to study the physical processes for film removal and estimate the temperature rise at the substrate surface. This model is applied to a case of paint removal from an aluminum substrate. Since the physical properties of paint is mainly determined by the polymer film, ${ }^{27}$ the average values of the thermophysical properties of polymers are used for numerical calculations. The thermophysical properties of aluminum ${ }^{28,29}$ and polymers are listed in Table I. The absorptivity of paints is very high ${ }^{30}$ and it is taken to be $80 \%$ in this study. The film thickness is chosen to be $1 \mathrm{~mm}$ in the calculations.

\section{RESULTS AND DISCUSSION}

The intensity distribution of $\mathrm{TEM}_{31}$ COIL beam of width and length $10 \mathrm{~mm}$ each is shown in Fig. 3. It should be noted that $M=3$ and $N=1$ correspond to $m=0,1,2,3$ and $n=0,1$, respectively, which means that the beam has four and two modes in the $x$ and $y$ directions, respectively. Due to the particular choice of the power distribution in each mode as

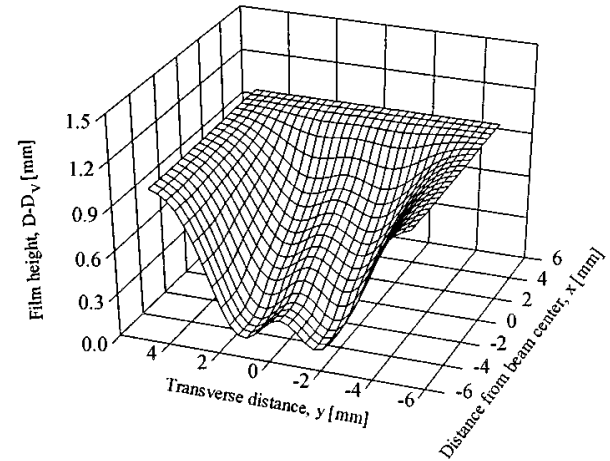

FIG. 4. Three-dimensional view of the film surface due to irradiation with a moving $\mathrm{TEM}_{31}$ COIL beam $\left(P=450 \mathrm{~W}, \nu=10 \mathrm{~cm} / \mathrm{s}, 2 l_{1}=2 w_{1}=10 \mathrm{~mm}\right)$.

given in Table II, the intensity is low at the beam center and high near the edges of the beam in both $x$ and $y$ directions as shown in Fig. 3. There are four major and four minor intensity peaks near the corners and central region, respectively.

The film surface and the temperature distribution at the substrate surface under the $\mathrm{TEM}_{31}$ COIL spot are shown in Figs. 4 and 5, respectively. At the front edge of the spot $\left(x=l_{1}\right)$ in Fig. 4 , the heating of the film begins. When the laser beam continues to move in the $x$ direction, the film in the path of the beam is heated up to the melting and vaporization points so that the film is removed by vaporization. Two valleys are formed in the irradiated region because the laser intensity has two peaks in the $y$ direction. The temperature distribution is symmetric with respect to the $y$ axis and it has two peaks as shown in Fig. 5. These peaks are located near the rear intensity peaks of the laser beam.

Figure 6 shows the cross section of the film after irradiation with a $\mathrm{TEM}_{31}$ COIL beam. The film contour resembles to the letter " $W$ " at low laser powers, while the film is vaporized away completely in the central region at higher laser powers. However, the removed width of the film in the

TABLE II. Power distribution for various TEM $_{m n}$ modes.

\begin{tabular}{|c|c|c|c|c|c|c|}
\hline \multirow[b]{2}{*}{ Laser modes } & \multirow{2}{*}{$\begin{array}{l}\text { Total power } \\
\qquad(\mathrm{kW})\end{array}$} & \multirow[b]{2}{*}{$n$} & \multicolumn{4}{|c|}{$\begin{array}{l}\text { Laser power distribution }(\mathrm{kW}) \\
\qquad m\end{array}$} \\
\hline & & & 0 & 1 & 2 & 3 \\
\hline \multirow{10}{*}{$\mathrm{TEM}_{31}$} & 0.45 & 0 & 0.0075 & 0.030 & 0.075 & 0.1125 \\
\hline & & 1 & 0.0075 & 0.030 & 0.075 & 0.1125 \\
\hline & 0.90 & 0 & 0.015 & 0.060 & 0.150 & 0.225 \\
\hline & & 1 & 0.015 & 0.060 & 0.150 & 0.225 \\
\hline & 1.40 & 0 & 0.023 & 0.093 & 0.233 & 0.350 \\
\hline & & 1 & 0.023 & 0.093 & 0.233 & 0.350 \\
\hline & 2.00 & 0 & 0.033 & 0.133 & 0.333 & 0.500 \\
\hline & & 1 & 0.033 & 0.133 & 0.333 & 0.500 \\
\hline & 2.25 & 0 & 0.041 & 0.166 & 0.417 & 0.625 \\
\hline & & 1 & 0.041 & 0.166 & 0.417 & 0.625 \\
\hline \multirow[t]{6}{*}{$\mathrm{TEM}_{00}$} & 0.40 & 0 & 0.40 & & & \\
\hline & 0.90 & 0 & 0.90 & & & \\
\hline & 1.40 & 0 & 1.40 & & & \\
\hline & 2.00 & 0 & 2.00 & & & \\
\hline & 2.50 & 0 & 2.50 & & & \\
\hline & 3.20 & 0 & 3.20 & & & \\
\hline
\end{tabular}




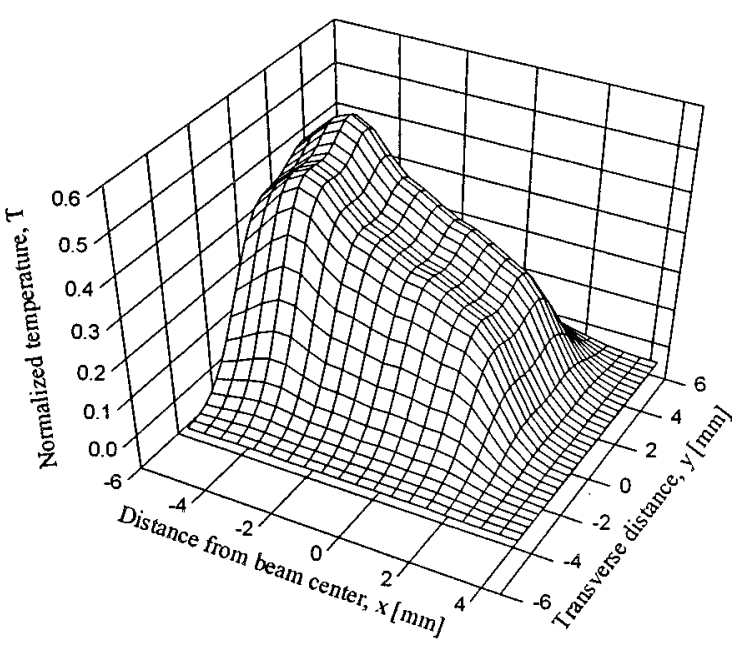

FIG. 5. Three-dimensional normalized temperature distribution at substrate surface due to irradiation with a moving TEM $_{31}$ COIL beam $(P=450 \mathrm{~W}$, $\left.\nu=10 \mathrm{~cm} / \mathrm{s}, 2 l_{1}=2 w_{1}=10 \mathrm{~mm}\right)$.

central region cannot be expected to increase greatly with increasing laser power because high intensity laser beams will remove the entire film and then irradiate the exposed region of the substrate surface. Therefore, the laser power will be utilized to heat up the substrate, which may damage the substrate due to melting or degrade its mechanical properties. Owing to these effects, the increase in the removed film width is limited when the laser power increases. The ideal situation is to remove the film completely without affecting the properties of the substrate.

The effect of laser beam scanning speed on film removal is shown in Fig. 7, which indicates that wider film is removed at lower scanning speeds. However, low scanning speeds will increase the film removal time and it may raise the substrate temperature which is similar to the situation encountered at high laser powers. The removed film width increases with the increase in the laser beam width as shown in Fig. 8, which means that a wider beam can be selected to remove more film if the laser power is sufficiently high.

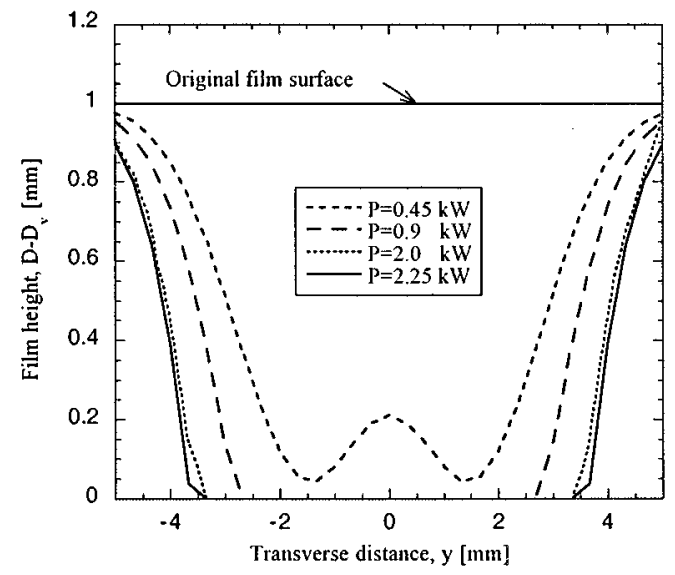

FIG. 6. Variation in the film thickness and width for various laser powers $\left(\mathrm{TEM}_{31}, \nu=10 \mathrm{~cm} / \mathrm{s}, 2 l_{1}=2 w_{1}=10 \mathrm{~mm}\right)$.

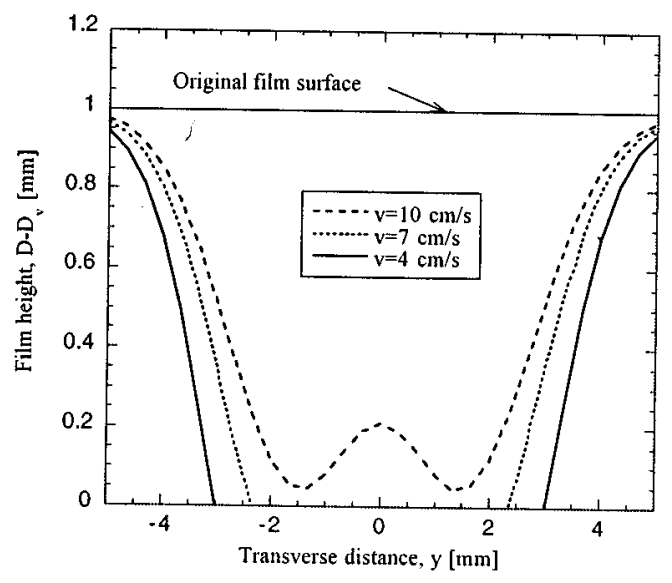

FIG. 7. Variation in the film thickness and width for various scanning speeds $\left(\mathrm{TEM}_{31}, P=450 \mathrm{~W}, \nu=10 \mathrm{~cm} / \mathrm{s}, 2 l_{1}=2 w_{1}=10 \mathrm{~mm}\right)$.

The removed film width and the maximum substrate surface temperature at different laser powers are presented in Fig. 9, which indicates a large increase in the temperature and a limited increase in the removed film width as the laser power increases. An optimum laser power is found to be about $1 \mathrm{~kW}$ at which relatively more film is removed and the maximum substrate surface temperature is low. If the laser power is higher than the optimum value, the removed film width increases a little but the maximum substrate surface temperature rises rapidly. It should be noted that the optimum laser power depends on the process parameters. For example, the optimum laser power will be higher than $1 \mathrm{~kW}$ if the laser scanning speed is larger than $10 \mathrm{~cm} / \mathrm{s}$, or the laser beam width is greater than $10 \mathrm{~mm}$. The optimum laser power can be obtained from the mathematical model of this article. There is a maximum value of the removed film width at which the substrate temperature reaches its melting point, which is about $6.4 \mathrm{~mm}$ in Fig. 9. When the laser power is less than a minimum value (about $500 \mathrm{~W}$ in Fig. 9), the laser power is insufficient to vaporize the film completely from the substrate.

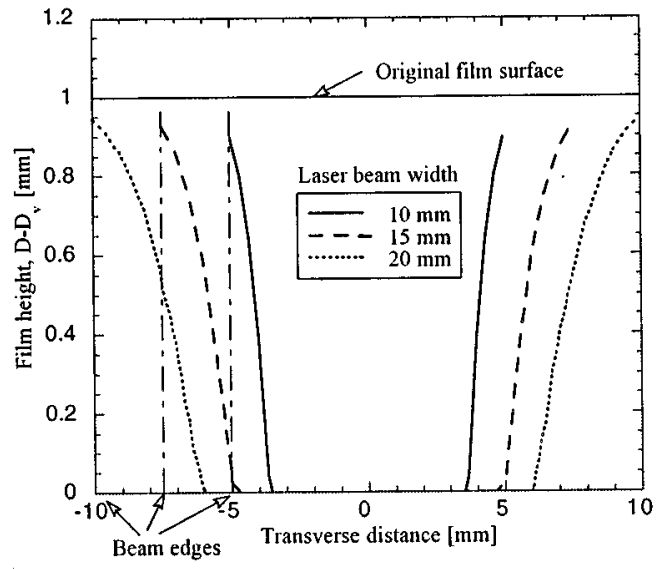

FIG. 8. Variation in the film thickness and width for various widths of the laser beam $\left(\mathrm{TEM}_{31}, P=2.25 \mathrm{~kW}, \nu=10 \mathrm{~cm} / \mathrm{s}, 2 l_{1}=10 \mathrm{~mm}\right)$. 


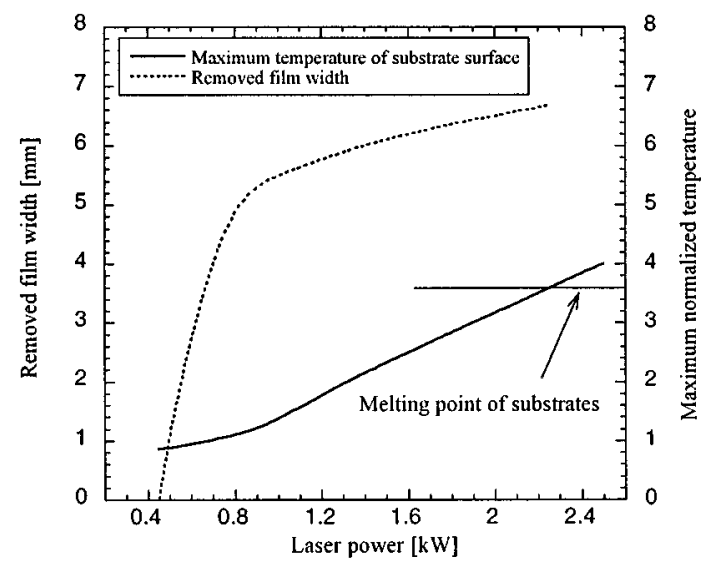

FIG. 9. Variation of the removed film widths and the maximum normalized temperature at the substrate surface with laser power $\left(\mathrm{TEM}_{31}, \nu=10 \mathrm{~cm} / \mathrm{s}\right.$, $\left.2 l_{1}=2 w_{1}=10 \mathrm{~mm}\right)$.

The $\mathrm{TEM}_{00}$ mode (Gaussian beam) is popular for laser materials processing. The three-dimensional intensity distribution of a square COIL Gaussian beam is shown in Fig. 10, which is similar to a circular Gaussian distribution except at the edges of the beam. The film surface produced by a square COIL Gaussian beam is shown in Fig. 11. Due to the cumulative effect of melting and vaporization on the film removal depth, more film is removed at the rear edge than at the front edge of the laser spot and the valley of the film surface is located at the central region of the rear edge. However, the maximum surface temperature occurs a little behind the beam center in the negative $x$ direction because of the advection effect associated with the relative motion between the laser beam and workpiece. The cross-sectional contour of the film produced by the $\mathrm{TEM}_{00}$ COIL beam resembles to the letter "V."

It is interesting to compare the film removal results obtained by using the $\mathrm{TEM}_{00}$ and $\mathrm{TEM}_{31}$ beams. The variations in the cross section of the film produced by the $\mathrm{TEM}_{00} \mathrm{COIL}$

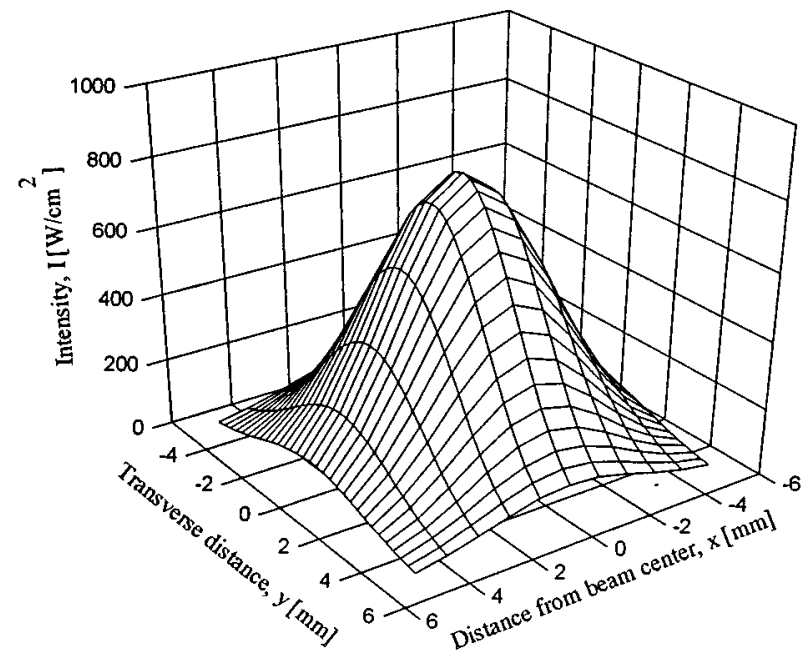

FIG. 10. Three-dimensional intensity distribution of a TEM ${ }_{00}$ COIL beam $\left(P=450 \mathrm{~W}, 2 l_{1}=2 w_{1}=10 \mathrm{~mm}\right)$.

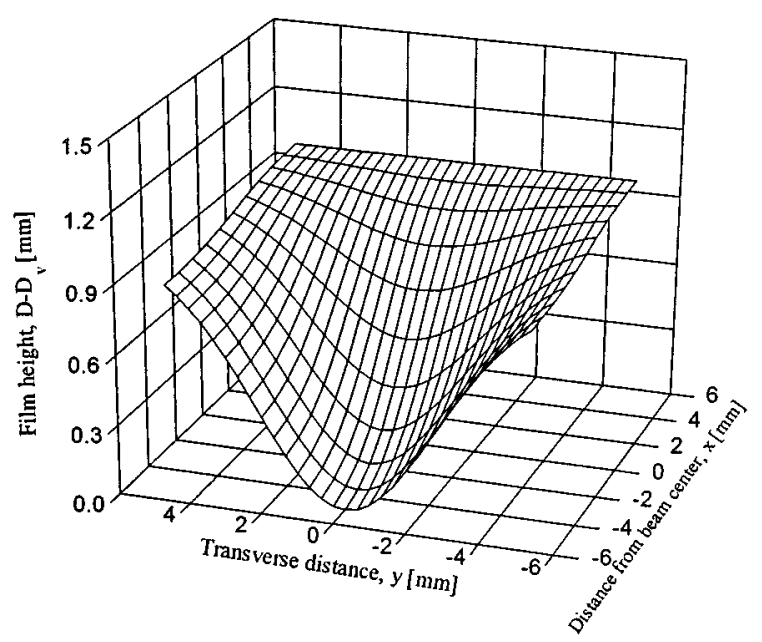

FIG. 11. Three-dimensional view of the film surface due to irradiation with a moving $\mathrm{TEM}_{00}$ COIL beam $\left(P=400 \mathrm{~W}, \nu=10 \mathrm{~cm} / \mathrm{s}, 2 l_{1}=2 w_{1}\right.$ $=10 \mathrm{~mm}$ ).

beam are shown in Fig. 12 for various laser powers. The trend is similar to the case of $\mathrm{TEM}_{31}$ in that the removed film width increases very little, while much of the laser energy is utilized to heat up the substrate when the laser power is high. Similarly, it is found that there is also an optimum laser power for the $\mathrm{TEM}_{00}$ COIL beam which is about $1 \mathrm{~kW}$, same as that of the $\mathrm{TEM}_{31}$ beam. This implies that the optimum laser power is independent of the laser mode.

The removed film widths and maximum substrate surface temperatures for the $\mathrm{TEM}_{31}$ and $\mathrm{TEM}_{00}$ COIL beams are compared in Figs. 13 and 14, respectively. The removed widths due to the $\mathrm{TEM}_{31}$ and $\mathrm{TEM}_{00}$ beams are almost identical when the laser power is less than the optimum power, but the width in the case of the $\mathrm{TEM}_{00}$ beam is a little higher than in the case of the $\mathrm{TEM}_{31}$ beam when the laser power is greater than the optimum value as shown in Fig. 13. This is because the intensities of the $\mathrm{TEM}_{00}$ beam at the transverse edges are higher than that of the $\mathrm{TEM}_{31}$ beam. However, the maximum substrate surface temperature caused by the

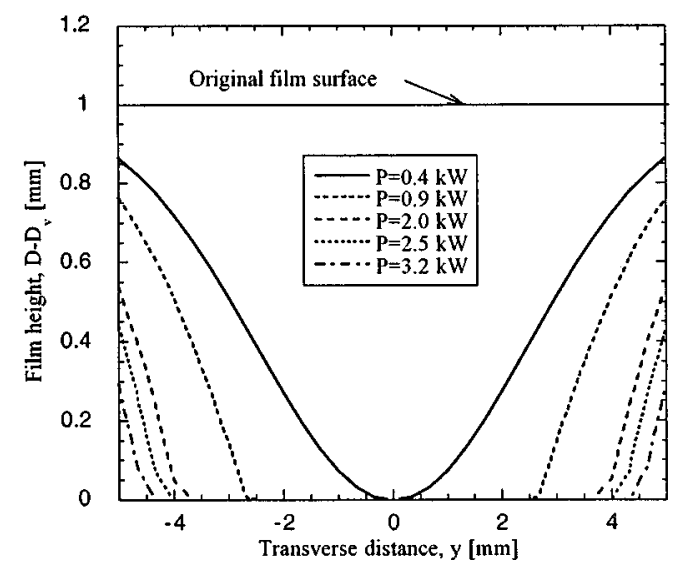

FIG. 12. Variation in the film thickness and width for various laser powers $\left(\mathrm{TEM}_{00}, \nu=10 \mathrm{~cm} / \mathrm{s}, 2 l_{1}=2 w_{1}=10 \mathrm{~mm}\right)$. 


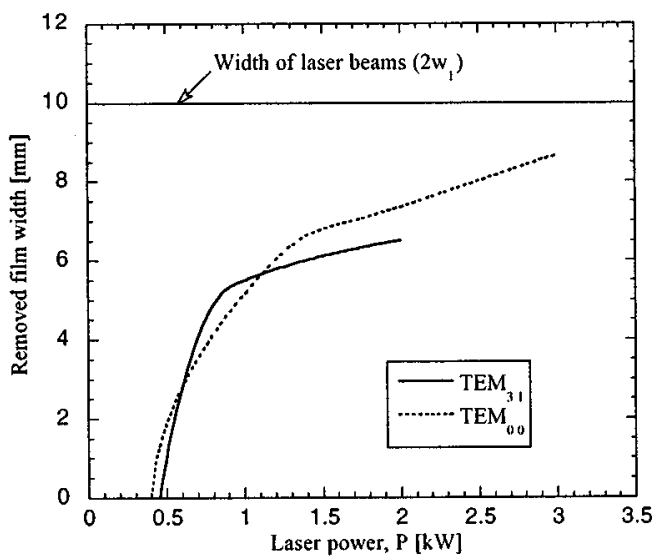

FIG. 13. Variation of the removed film widths with laser powers $(\nu$ $\left.=10 \mathrm{~cm} / \mathrm{s}, 2 l_{1}=2 w_{1}=10 \mathrm{~mm}\right)$.

$\mathrm{TEM}_{31}$ beam is always higher than in the case of the $\mathrm{TEM}_{00}$ beam due to higher peak intensities of the $\mathrm{TEM}_{31}$ beam. Uniform intensity distribution is expected to remove more film without raising the substrate temperature significantly. ${ }^{31}$

\section{CONCLUSIONS}

A mathematical model for large-area film removal with a chemical oxygen-iodine laser is developed in this study. This model can be used to study the melting and vaporization phenomena during film removal and estimate the substrate surface temperature. The cross section of the film assumes the shape of the letter $\mathrm{W}$ after $\mathrm{TEM}_{31}$ COIL beam irradiation and $\mathrm{V}$ after $\mathrm{TEM}_{00}$ beam irradiation at low laser powers. The film in the central region of the laser spot is removed completely due to vaporization at higher laser powers. The removed film width and the substrate surface temperatures increase as the laser power increases, and the beam width and scanning speed decrease. There is an optimum laser power at which relatively wider film is removed and the substrate surface temperature is not very high. The optimum value depends on the process parameters, but not on the laser

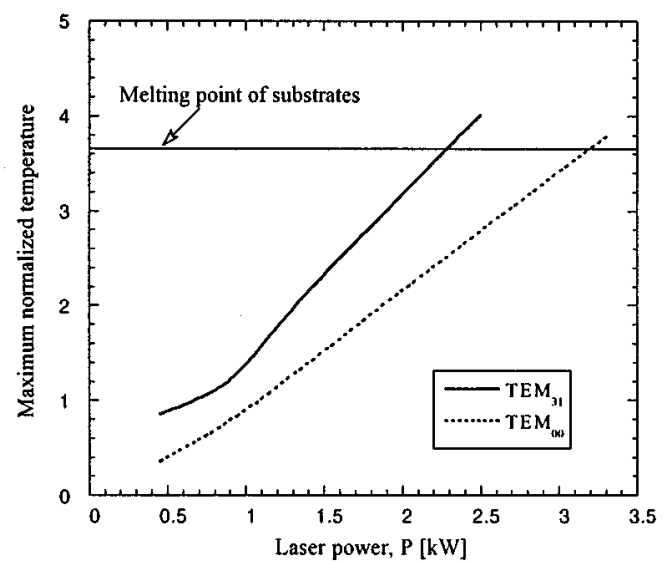

FIG. 14. Variation of the maximum normalized temperature at the substrate surface with laser powers $\left(\nu=10 \mathrm{~cm} / \mathrm{s}, 2 l_{1}=2 w_{1}=10 \mathrm{~mm}\right)$. modes. The removed film width by both $\mathrm{TEM}_{31}$ and $\mathrm{TEM}_{00}$ COIL beams are close to each other, but the $\mathrm{TEM}_{31}$ beam causes higher temperature at the substrate surface because of its higher peak intensities. Laser beams with high peak intensities may damage the substrate or degrade its mechanical properties. Uniform intensity distribution is expected to be suitable for large-area film removal.

\section{ACKNOWLEDGMENT}

This work was done at the Center for Research and Education in Optics and Lasers (CREOL) in the University of Central Florida under AFOSR Contract No. F49620-93C0063.

${ }^{1}$ J. F. Foley, Metal Finishing 90, 48 (1992).

${ }^{2}$ C. M. Young, W. M. Moeny, R. D. Curry, K. McDonald, and J. T. Bosma, in Novel Applications of Lasers and Pulsed Power, edited by R. D. Curry (SPIE, San Jose, CA, 1995), Vol. 2374, pp. 2-9.

${ }^{3}$ P. Lavoi, Laser Focus World, 75 (1994).

${ }^{4}$ K. E. Abbott, Metal Finishing 94, 33 (1996).

${ }^{5}$ G. Schweizer and L. Werner, in Gas Flow and Chemical Lasers, edited by W. L. Bohn, and H. Hugel (SPIE, Germany, 1994), Vol. 2502, pp. 57-62.

${ }^{6}$ A. Raiber, B. Plege, and R. Holbein, in Gas Flow and Chemical Lasers, edited by W. L. Bohn and H. Hugel (SPIE, Germany, 1994), Vol. 2502, pp. 670-675.

${ }^{7}$ J. M. Hickey III and L. E. Hise, in Intelligent Robots and Computer Vision XIII: Algorithms and Computer Vision, edited by D. P. Casasent (SPIE, Boston, MA, 1994), Vol. 2353, pp. 503-512.

${ }^{8}$ E. Schubert, K. Schtte, A. Emmel, and H. W. Bergmann, in Gas Flow and Chemical Lasers, edited by W. L. Bohn and H. Hugel (SPIE, Germany, 1994), Vol. 2502, pp. 656-663.

${ }^{9} \mathrm{~L}$. Li, W. M. Steen, P. J. Modern, and J. T. Spencer, in Laser Materials Processing and Machining (SPIE, Frankfurt, Germany, 1994), Vol. 2246, pp. 84-95.

${ }^{10}$ Sp. G. Pantelakis, Th. B. Kermanidis, and Haidemenopoulos, Theor. Appl. Fracture Mech. 25, 139 (1996).

${ }^{11}$ W. E. McDermott, N. R. Pchelkin, D. J. Benard, and R. R. Bousek, Appl. Phys. Lett. 32, 469 (1978).

${ }^{12}$ K. A. Truesdell, C. A. Helms, and G. D. Hager, "COIL Development in the USA," 25th Plasmadynamics and Lasers Conference, AIAA 94-2421, June 1994.

${ }^{13}$ J. E. Scott, J. L. R. Shaw, K. A. Truesdell, G. D. Hager, and C. A. Helms, in Design Considerations for the Chemical Oxygen-Iodine Supersonic Mixing Nozzle, 25th Plasmadynamics and Lasers Conference, AIAA 942436, 1994.

${ }^{14}$ H. Fujii, S. Yoshida, M. Iizuka, and T. Atsuta, J. Appl. Phys. 66, 1033 (1989).

${ }^{15}$ H. Fujii and T. Atsuta, "Current Status of Industrial COIL Development," Third International Workshop on Iodine Lasers and Applications (SPIE, Bechyne Castle, Czechoslovakia, 1992), Vol. 1980, pp. 148-152.

${ }^{16}$ F. Wani, N. Naitou, T. Nagai, M. Iizuka, H. Tsuji, and H. Fujii, in Proceedings of Laser Advanced Materials Processing (LAMP '92), Niigata, Japan, June 1992, pp. 127-132.

${ }^{17}$ K. A. Truesdell, T. Lonergan, C. Wisniewski, K. Healey, J. Scott, and C. Helms, "COIL Thermal Management," 25th Plasmadynamics and Lasers Conference, AIAA 94-2441, June 1994

${ }^{18}$ S. Phipps, C. A. Helms, and K. A. Truesdell, "Compact cw Supersonic Chemical Oxygen Iodine Laser (COIL)," 25th Plasmadynamics and Lasers Conference, AIAA 94-2453, June 1994.

${ }^{19} \mathrm{P}$. V. Avizonis and K. A. Truesdell, "Historical Perspectives of the Chemical Oxygen-Iodine Laser (COIL)," 25th Plasmadynamics and Lasers Conference, AIAA 94-2416, June 1994.

${ }^{20}$ T. Fujioka, Infrared Phys. 32, 81 (1991).

${ }^{21}$ T. Atsuta, K. Yasuda, T. Matsumoto, T. Sakurai, and H. Okado, in Conference on Lasers and Electron-Optics (CLEO) '94, Vol. 8, 1994 OSA Technical Digest (Optical Society of America, Washington, DC, 1994), p. 351.

${ }^{22}$ H. Fujii, "COIL Development in Japan," 25th Plasmadynamics and Lasers Conference, AIAA 94-2410, June 1994. 
${ }^{23}$ A. Kar, J. E. Scott, and W. P. Latham, J. Laser Appl. 8, 125 (1996).

${ }^{24}$ A. Kar, J. E. Scott, and W. P. Latham, J. Appl. Phys. 80, 667 (1996).

${ }^{25}$ J. Xie and A. Kar, J. Laser Appl. 9, 77 (1997).

${ }^{26}$ C. L. Chan and J. Mazumder, J. Appl. Phys. 62, 4579 (1987).

${ }^{27}$ D. Stoye, Paints, Coatings and Solvents (VCH GmbH, Weinheim, 1993), pp. 3-7.

${ }^{28}$ Smithells Metals Reference Book, 6th ed., edited by E. A. Brandes (Butterworths, Boston, 1983).
${ }^{29}$ Y. S. Touloukian and C. Y. Ho, Thermophysical Properties of Selected Aerospace Materials, Part II: Thermophysical Properties of Seven Materials (Purdue University, 1977).

${ }^{30}$ J. A. Hopkins, V. V. Semak, and M. H. McCay, in Laser Material Processing, Proc. ICALEO '94, Vol. 2500, edited by T. O. McCay, A. Matsunawa, and H. Hugel (Laser Institute of America, Orlando, Fl, 1994), pp. 838-845.

${ }^{31}$ B. Godard, P. Murer, P. Laborde, M. Stehle, J. Bonnet, and D. Pigache, Lasers and Electro-Optics Europe, Amsterdam, Netherlands, 1994, p. 81. 